\title{
The plight of migrants during COVID-19 and the impact of circular migration in India: a systematic review
}

\author{
Joshy Jesline (i) ${ }^{1}$, John Romate (iD ${ }^{1}$, Eslavath Rajkumar (1) ${ }^{1 凶} \&$ \\ Allen Joshua George (i) ${ }^{1}$
}

As per the reports of WHO, the COVID-19, first reported in December 2019, put the whole world in an unprecedented crisis and lingering uncertainty with innumerable deaths, generalised economic depression, unemployment, quarantine, unavoidable lockdown, and travelban that was imposed globally as a necessity to tackle the pandemic. Among the populace, the migrants were found to be one of the most vulnerable groups in this lockdown, as their very livelihood came to a complete standstill. This review-paper aims to investigate in detail the multiple facets of adversities the migrants went through in India during the lockdown and the socio-psychological impact of circular migration. Following the PRISMA (Preferred Reporting Items for Systematic Reviews and Meta-Analyses) guidelines, studies on migrant workers during COVID-19 and on circular migration were searched. Database searches on Scopus, PubMed, and PsychNet and manual searches on Google Scholar were carried out. From the initially identified 15,697 articles, 15 articles that met the inclusion criteria were chosen for review. The findings highlight the different plight of the migrants, who had the pressing need to head back home to safety despite the acute financial crisis and the travel problems. The poor quality of the relief camps with meagre rations and lack of facilities especially put the women and children in distress and generated a lot of psychosocial issues. The present study urges the mental health-care professionals to groom themselves for facing the challenges of a surge in mental illnesses by taking necessary measures. It also emphasises the need to establish a strong ethical alliance between the local population, health systems, local government mechanisms, and human rights associations in order to take a relook at the national migration policies.

\section{Introduction}

he year 2019 brought with it a new pandemic, the COVID-19 that was first reported in the month of December as per the reports from World Health Organisation, and put the whole world in an unprecedented crisis, that has pushed it into a state of lingering uncertainty (WHO, 2020). The coronavirus disease 2019, commonly known as the COVID-19

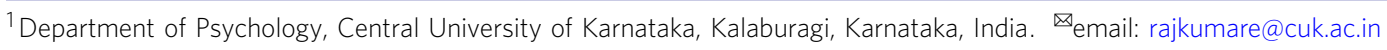


pandemic, a corollary of severe acute respiratory syndrome coronavirus-2 infection, has led to a global public health crisis, innumerable deaths, generalised economic depression, redundancy, and quarantines (Aragona et al., 2020). The virus brought about a massive change to the existing systems and generated a whirlpool of hurdles that the people had never faced before or had no idea how to overcome. This eventually created overwhelming fear and mounting anxiety among the people due to the novelty of the crisis, the uncertainty it brought with it about how and when the situation will get back to normal, as well as the dread of an impending doom (Mishra and Sayeed, 2020). One of the biggest challenges was the complete lack of an effective treatment method or a preventive vaccine to overcome the virus (Rolland, 2020). To make matters worse, the pandemic affected people not only physically but also psychologically, economically, socially, and politically. People belonging to various socioeconomic strata were affected adversely in this situation, regardless of their social status, as everyone had fallen prey to this crisis in one way or another. It is undeniably true that the life in the pandemic era effected a far-reaching change in the way people think, work and interact with one another around the world (Aragona et al., 2020). What is more, it has also taught the world the new normal ways of human relationships and social distancing, which are sure to linger on for quite a while (Ram, 2020; Rolland, 2020). It has also provided the world a lesson about the worthlessness of the rat race and the fragility of human life. It is certainly true that the pandemic has led the world to a paradigm shift in the attitude and behaviour of people as never before.

The pandemic brought with it lockdowns and travel-bans that were imposed by the governments all over the world as a necessity to tackle the pandemic and to rein in its outspread. However, the lockdown upset the daily routines of the people especially the working class who were put in a major financial predicament (Chander et al., 2020). A new normalcy of surviving in a state of constant panic came into place, with the people being asked to live in this uncertainty for a longer duration than what was anticipated in the beginning of the pandemic. A batch of novel practices came into existence as part of rigorous mitigation efforts, such as, "social distancing, household quarantine, facemasks, vigilant sanitisation and hand washing, and avoidance of public gatherings, public transportation etc." (Rolland, 2020). As time passed and the situation became worse, the pandemic has slowly unmasked its harsh reality and people have started grasping this truth that the current state of the situation is going to last longer than what was presumed of it in the beginning, and this has affected them rather drastically. The transformational process of adapting to this pandemic risk as a public or global calamity, while dealing with the fear of contracting COVID-19, and managing the disease, is highly exhausting and not doable by all (Rolland, 2020).

The daily wagers were the worst sufferers of this lockdown. With the enforcement of the lockdown, not only were they without jobs but also were frustrated because of the cessation of their daily income on which they survived (Ram, 2020). Their very livelihood came to a complete standstill; as a result, they could not meet theirs as well as their families' daily needs (Chakma, 2020). The migrants were found to be the most vulnerable among the working class to come under this economy fallout (Nanda, 2020). The situation affected people belonging to all classes; moreover, it has exposed in the bare open the blatant disparities that exist in the socio-economic and health-care facilities (Aragona et al., 2020). In addition, it has been found that the perils of sickness and deaths vary colossally by "social location, such as, race, social class, gender, age, ability, and geographic location" (Rolland, 2020). There were many reported cases of suicide and suicidal attempts especially by people from economically lower classes, as they were not able to cope with the problems stemming from the loss of job and income (Kumar and Vashisht, 2009; Mukhra, 2020; Nelson, 2020).

In addition, the mental strain this pandemic imposed on the common people was especially enormous. One such group that was highly and adversely affected by this crisis situation was the migrants, who had to move out to different parts of the country in search of jobs to sustain their families (Singh, 2020a, 2020b, 2020c). There are about 100 million internal migrant workers in India, and most of them are daily-wage labourers who have travelled out from different states like Uttar Pradesh, Bihar, Jharkhand, Odisha, West Bengal, etc. to other states in search of unskilled or semi-skilled jobs (Hazarika, 2020). Based on the data obtained from the National Sample Survey (NSS) 2007-2008, out of the total workforce in India, about $28.3 \%$ were migrants. According to 2011 census, about $37 \%$ of India's total population were found to be migrants (Singh, 2021). This was a climb of 139 million migrants from what was reported in 2001 census (Census of India, 2011; Singh, 2020a, 2020b, 2020c).

These migrants too were trapped in the lockdown with no jobs and no money, facing major economic setback, besides being isolated from their families due to the sudden lockdown (Mishra and Sayeed, 2020). While India's population of 1.3 billion people could not but come to terms with the changes of imposed social distancing, millions of migrant workers in India had other daunting tasks also to confront with (Londhe, 2020). The concept of social distancing bears no meaning for the migrants because of the persistence of even more pressing and nagging problems of insecurity and hunger. Based on the data obtained from Census 2011, it was found that there was a rise in total number of migrants by $30 \%$ from that of 2001 , whose major destinations are growth centres and states like Delhi, Maharashtra, Tamil Nadu, Gujarat, Andhra Pradesh and Kerala (Census of India, 2011; Dandekar and Ghai, 2020; Nanda, 2020). Even though, the lockdown situation affected the community at large and people were obliged to stay at home, the migrants could not even be in the comfort of being locked in with their families; instead, they were destined to be stuck in a migrant land with no means to survive (Kumar et al., 2020). Therefore, this community had to endure more appalling hardships than anyone else, not only financially but also socially and mentally (Aragona et al., 2020; Singh, 2020a, 2020b, 2020c).

In order to alleviate the suffering of migrants it is necessary to investigate, understand, and analyse the hardships they have been undergoing. In-depth explorations of the studies in the Indian context dealing with circular migration and their psychological impact are needed to foster greater awareness among the public and to introduce new measures that can be adopted to safeguard the rights of the migrants.

This review-paper aims to study in detail the multiple facets of the predicaments the migrant workers were going through in the Indian context during the pandemic and the lockdown. Its main objective is to focus on the hardships that have led the migrants to a circular migration or reverse migration and the adversities that have been brought about by circular migration during the pandemic upon the migrants. The study also aims to shed light on the psychological toll inflicted by this pandemic on the migrants and the resultant reverse migration. Furthermore, it focuses on the means to address the issues concerning their mental healthcare, and makes recommendations on the measures to protect their human rights and safeguard their lives and livelihood.

\section{Methods}

To the best of the authors' knowledge, this is the first systematic review that has specifically focused on the plight of the migrant 
workers during the pandemic and the issues revolving around circular migration in the Indian context. The consequences of this pandemic have put the world in a state of impending doom and therefore, there is a compelling need to address the situation especially of the migrants who are among the groups, which are most affected by the adverse outcomes of COVID-19 and subsequent restrictions on mobility. A systematic review helps to synthesise the data related to this from all available sources and to integrate them in order to efficiently reach and promote awareness among health-care professionals, policy makers, administrative staff, future researchers, and the general public. The findings of this study could therefore be used for formulating new strategies for the betterment of migrant workers.

Types of studies included. Studies on migration and circular migration of Indians during the COVID-19 crisis were considered to be included in the current systematic review, regardless of the type of study, research design, or the outcomes. However, studies on emigrants, immigrants, and migrants in other countries were excluded from the study.

Subjects of the study. The population for the study were unskilled migrant workers in India, who were among the most affected during the lockdown due to their low socio-economic status, besides being increasingly prone to mental health issues.

Search strategy. The search string used in Scopus was: TITLEABS-KEY ("circular migration") OR TITLE-ABS-KEY (migration) OR TITLE-ABS-KEY (migrant) AND TITLE-ABS-KEY (covid) OR TITLE-ABS-KEY (covid-19); in PsychNET (Abstract: "circular migration" OR Abstract: "migration" $O R$ Abstract: "migrant" AND Abstract: "covid" OR Abstract: "covid-19" AND Publication); and in PubMed ("circular migration" [Title/ Abstract] OR "migration" [Title/Abstract] OR "migrant" [Title/Abstract]) AND "covid" [Title/Abstract]) OR "covid-19" [Title/Abstract]).

Data management. All pinpointed references were imported to Zotero, a bibliographic reference management tool, and all duplicates were removed. The de-duplicated citations in Zotero were imported to the data extraction form for coding.

Selection of studies. The first and third authors simultaneously screened the articles for the titles and abstracts and did the initial screening and data extraction independently. Articles that dealt with the plight of migrant workers during COVID-19 pandemic were included for the full text review. After the primary screening, the selected articles were reviewed for full text reading to determine their eligibility. The articles were selected if they were falling under the time-period of 2019-20 and discussed the plight of migrants during the lockdown and also addressed their psychological issues during this crisis in the Indian context. Final decision on the eligibility and the reasons for exclusion of studies were documented on the data extraction form.

Study characteristics. The final sample for the systematic review included 15 studies, which were all published in the year 2020 . Most of the studies were descriptive and qualitative in nature $(n=12)$ and discussed the plight of the migrants and the various adversities encountered by them in India during the lockdown, while the others $(n=3)$ were quantitative in nature that addressed in-depth the psychological issues faced by the migrants. All the articles were based on the Indian context, and most of the articles were pan Indian in their approach, while some articles $(n=4)$ focused on conditions of migrants in their respective states or cities alone, specifically Chandigarh, Delhi, Bangalore and Kolkata. The articles discussed the various economic, social and psychological issues faced by the migrants. Some articles $(n=8)$ also elaborated on the steps taken by the government and made suggestions about policies that can be adopted to better the lives of the migrants. Among this, some studies $(n=3)$ also focused on making psychological interventions to help the migrants (Chander et al., 2020; Singh, 2020a, 2020b, 2020c; Kumar et al., 2020).

The characteristics and main findings of these studies are summarised and presented in Table 1.

\section{Results}

Identification of the studies. In total, 15,697 studies were detected through database searching; among which 15 studies met the inclusion criteria and were further analysed for the present review. (The PRISMA flow diagram is shown in Fig. 1). Out of the 15,697 studies, 450 were from PsychNet, 14,988 were from PubMed, 229 from Scopus and 30 from Google Scholar. After the initial screening (which included the removal of duplicates), 106 articles were selected and assessed for eligibility, from which 91 studies were excluded and the final 15 were selected.

Distribution of migrants. Based on the data obtained in the Census 2011, it was found that the distribution of migrants to the total population across cities were, Delhi $43.1 \%$, Mumbai, 54.9\%, Kolkata 40.8\%, Chennai 51.8\%, Bangalore 52.3\%, Hyderabad 64.3\%, Ahmedabad $48.7 \%$ and Pune $64.8 \%$ (Census of India, 2011). As per the reports from a study, it was found that the highest number of COVID-19 cases as of $13^{\text {th }}$ April 2020 was reported in Delhi with 898 cases followed by Mumbai with 880 . The share of COVID-19 cases from these metropolitan cities to the total percent was 38\% (Bhagat et al., 2020).

Plight of migrants. All the studies focused on the various problems that the crisis has brought for the migrants, including the psychological and social issues. Out of the articles chosen for the current systematic review, the findings from a study (Kumar et al., 2020) on the psychological impact of the pandemic on the migrants $(n=98)$, revealed that about $63.3 \%$ of participants underwent loneliness and around $48 \%$ of them felt that there was a decrease in their social connectedness. Also, they found that roughly $50 \%$ experienced fear of death, around $58.2 \%$ individuals experienced frustration and tension, about $51 \%$ felt irritable and anxious, and three fourth of the participants were diagnosed with depression.

Statistics obtained from studies also suggested that almost only $4 \%$ of the total population of the migrants received rations that were allotted by the government, and $29 \%$ did not receive rations despite having ration cards (Farooqui and Pandey, 2020). Almost $90 \%$ of the migrants either faced loss of pay or a reduction in their salary (Shahare, 2020). International Labour Organization (ILO) estimated a decline of $22.6 \%$ in the wages of migrant workers post lockdown (Gothoskar, 2021). A survey conducted across 179 districts in India from May 30, 2020 to July 16, 2020 found that around $35 \%$ of the migrants went without any meal the whole day (Pandit, 2020).

The findings from some articles focused on circular migration and its adverse consequences $(n=5)$, while a few other articles reported the problems of discrimination faced by migrants belonging to the disadvantaged communities $(n=2)$. Some articles also emphasised the financial crisis created by this pandemic $(n=4)$, which was particularly acute for the migrants. All the studies shed light on the psychological issues faced by the migrants and among this, a few studies $(n=3)$ also suggested 


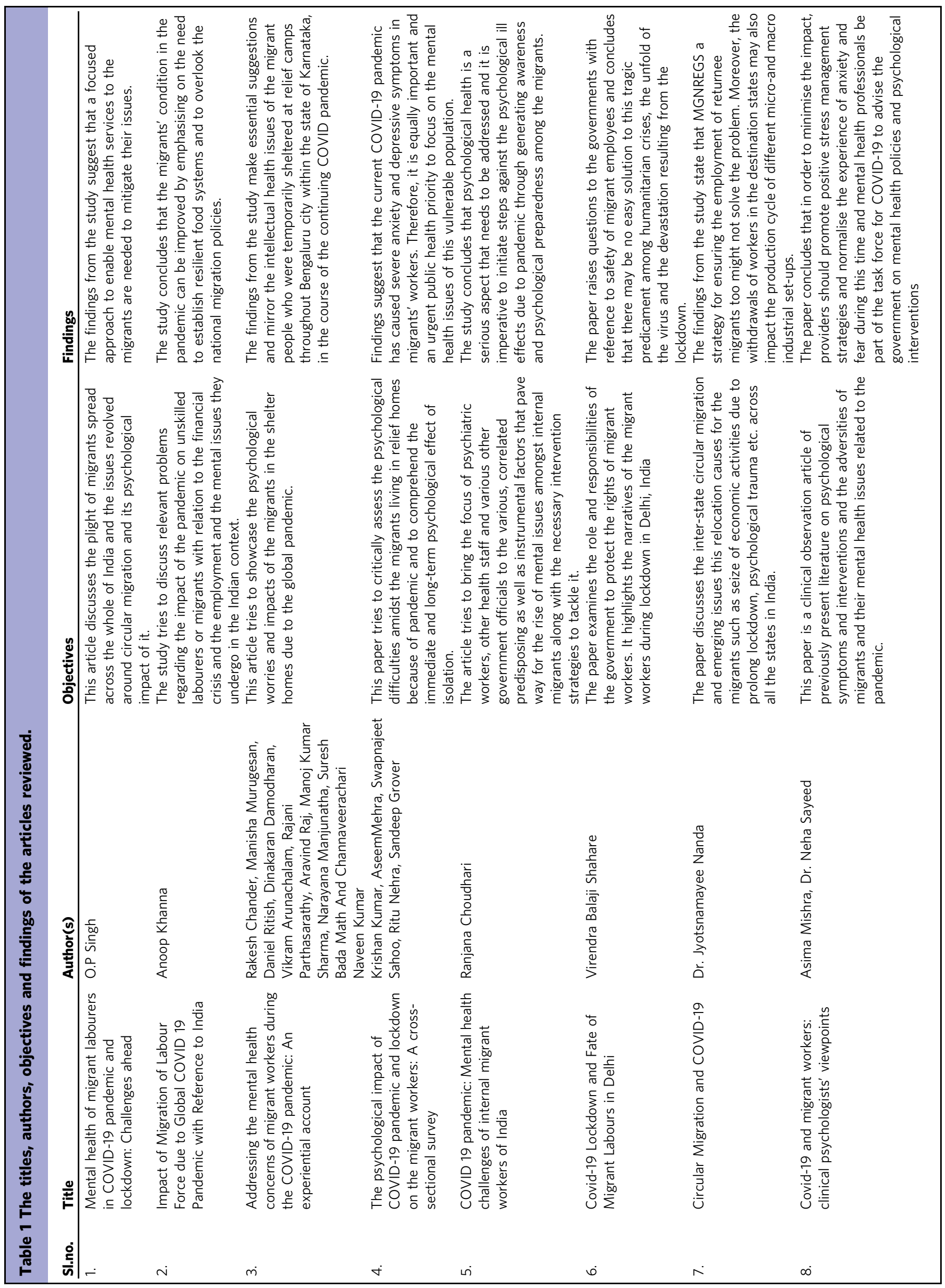




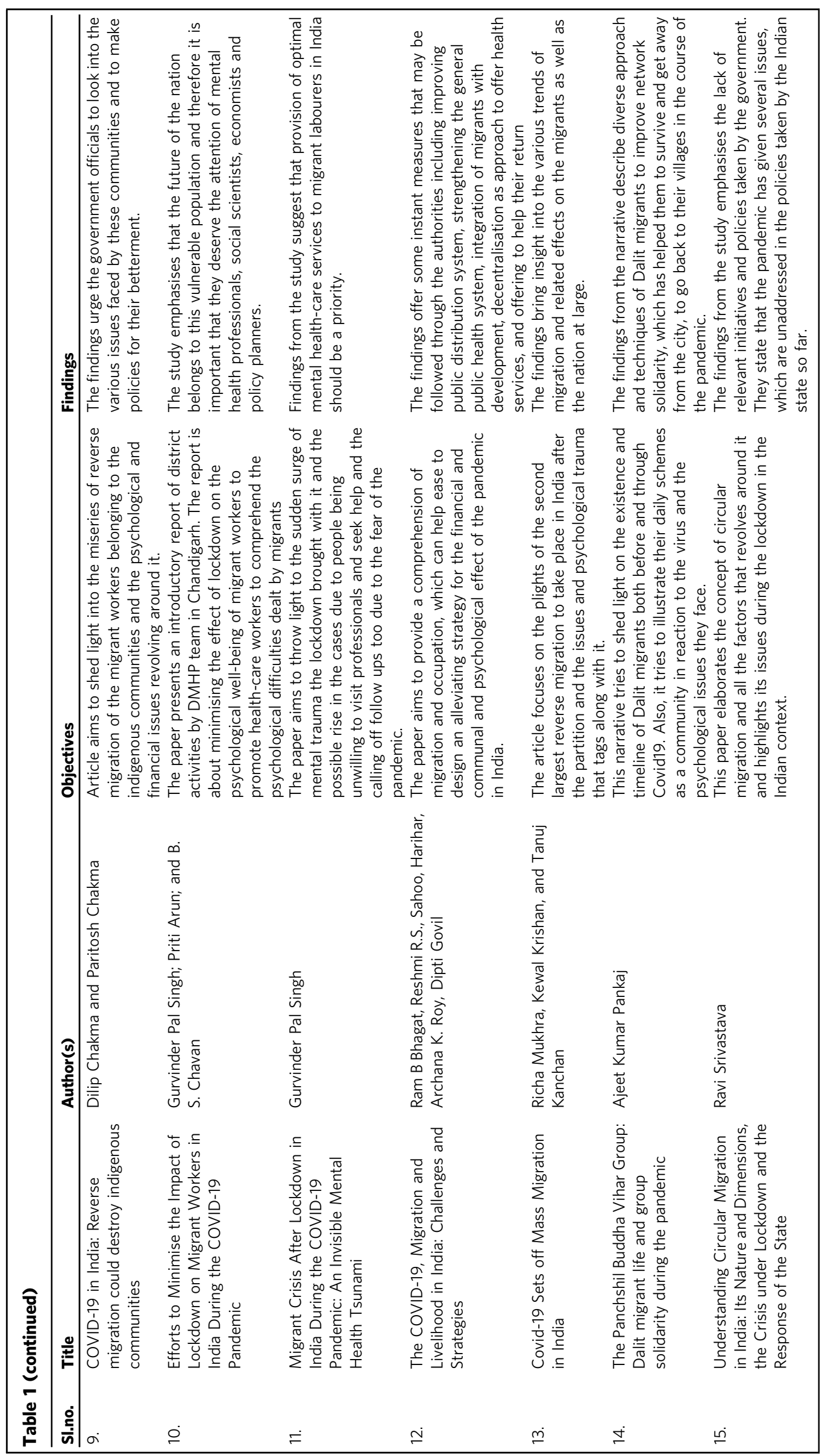




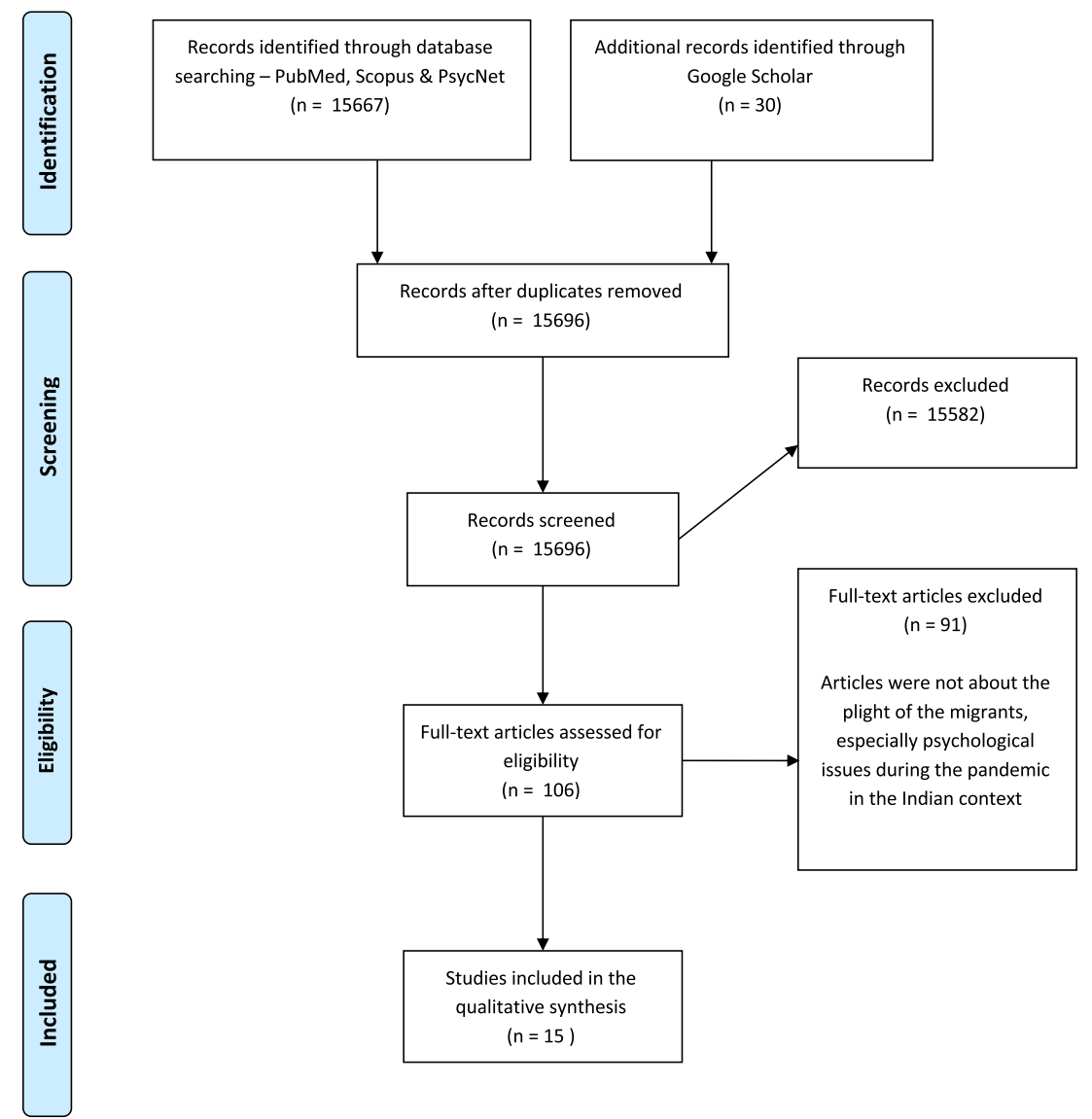

Fig. 1 The PRISMA flow diagram. Stages involved in finalizing the articles for analysis after obtaining the data.

interventions for the migrants (Chander et al., 2020; Singh, 2020a, 2020b, 2020c; Kumar et al., 2020). Many studies $(n=8)$ also pointed out the urgent need for revising the existing government-policies and taking new initiatives by the government for the betterment of the migrant workers.

Among the 15 studies, one study (Chander et al., 2020) reported visiting various spots across the city $(n=140)$, contacting around 5048 migrants and offering assistance to nearly 3944 migrants. In another study under the District Mental Health Program, Chandigarh, many migrants $(n=61)$ were attended to for their mental health issues and taken care of (Singh, 2020a, 2020b, 2020c). In the same city, another study was carried out among migrants $(n=98)$, which found that the majority of the participants were facing one or the other mental health issues and made interventions on a limited scale (Kumar et al., 2020).

\section{Discussion}

One of the key elements and an integral factor contributing to development among the human civilisation is migration (Nanda, 2020). Migration happens at both individual and community levels, and occurs due to multiple reasons such as the lookout for better job opportunities, improved living conditions and for enhanced productivity and thereby greater income (Raj, 1981; Shahare, 2020). Migration takes place based on the various vital resources that are available in the ecosystem (Ram, 2020). The practice of migration has happened from time immemorial and can be traced from the beginning of humanity, as it first existed in the form of nomads who moved in groups from one place to another in the lookout for better resources, and later on as invasions by various rulers (Rolland, 2020).
Migration is regarded as a continuous process that is common to all living beings (Virupaksha, 2014). There are two major types of migration: one that takes place within a country across a district or a state-border, which is known as internal or national migration; and the other a migration that involves crossing international borders, which is referred to as external or international migration (Bhagat, 2020a). Migrants associated with these types of migration are called in-migrants and out-migrants respectively (Sinha, 2005). Further, based on the place of origin and destination, migration can be classified into four categories: (i) rural-rural, (ii) rural-urban, (iii) urban-urban and (iv) urban-rural (Amin, 2018; Kishore and Kiran, 2013). The types of labour migration can be broadly classified as (i) Permanent, (ii) Commuting, and (iii) Circular (Haas and Osland, 2014). Permanent refers to the situation when the migrant does not intend to return to their native lands. Commuting refers to the regular movement between an individual's home and work, which is characterised by the separation between the workplace and residence (Colla et al., 2017). Circular migration is a situation where the migrants do not stay in the migrated lands forever but instead go back to their native lands after some time, and then might move again to a different place (Gomathi, 2014).

In general, the migrants go to their destinations to fulfil their livelihood/career aspirations and/or to satisfy their basic requirements, but they return to their places of origin after a certain period to settle down, which is a "circular" process (Ghosh, 1985). "Hence circular migration is viewed as a cyclic journey of the migrants, which encompasses with their living pattern in two worlds i.e., urban insecure employment and stable homeland" (Nanda, 2020). 
According to the National Sample Survey (NSS) and the India Human Development Survey (IHDS), the migrant labourers are mainly from rural areas and come from very poor backgrounds and belong to the lower social classes like the Scheduled Castes (SC), Scheduled Tribes (ST) and Other Backward Classes (OBC) (Shahare, 2020). According to the Organisation for Economic Cooperation and Development (OECD), the inter-state migration in pursuit of an occupation every year around the world was estimated to be around 9 million, and this is acknowledged as "temporary, contingent and non-standard" in nature with minimal access to societal perks and labour privileges (Chander et al., 2020, p.1). The administrative and socio-cultural barriers and the language differences in addition to geographical variance further hinder the process of migration (Aragona et al., 2020). The migrant workers are inclined to falling prey to adverse mental health impacts of various traumas created through interfaces of multiple factors such as, "abject poverty, malnutrition, cultural bereavement, loss of religious practices and social protection systems, malalignment with a new culture, coping with language difficulties, changes in identity, substance abuse, poor access to health-care, in addition to the poor living conditions and financial constraints", as a result of migrating to a new state (Choudhari, 2020, p. 5).

A large majority of the migrants are daily wagers who have low-income and poor living conditions that are dilapidated, unhygienic and scarce of basic amenities like clean water supply, and electricity (Kusuma et al., 2014). Most of the migrants are slum-dwellers with inadequate sanitation facilities and are forced to go for open defecation because of the lack of lavatories. As the migrants are not used to the food of the lands of their migration, many of them turn towards fast food centres, which deprives them of nutritious and healthy diets (Babu et al., 2017). The above-mentioned factors have made them susceptible to multiple physical and mental health problems (Chander et al., 2020). There are no government machinery, department, board or other direct administering body to address the grievances of these migrant workers; neither do they have any rights or privileges in the regions in which they work or in the villages to which they belong (Nirmala, 2020).

Upon the rise of the pandemic, the migrants were among the groups of victims who were acutely affected by the lockdown (Choudhari, 2020). These daily wagers are said to be the weakest and socially neglected community that forms the classic nobodies among Indian citizens (Shahare, 2020).

The migrants were trapped in their migrated lands, far away from their families and loved ones with minimal health-care facilities, poor living conditions, besides being devoid of a job and having no money or means to survive (Ram, 2020). The migrants are more likely to fall prey to various traumas emanating from all three domains- social, psychological, and emotional, which stem from the dread of being discriminated and ignored by the local community around them and the grave concerns that arise about the safety and comfort of their families in their native places (Kumar et al., 2020).

Circular migration, as a result of the pandemic, generated severe stress, tension, despair, addiction to substance use, and self-harm behaviour among the migrants. In addition, they had greater concerns that deeply affected them, such as, "uncertainty about the duration of the lockdown; desperate longing to travel and meet their families; fear of being abandoned/deserted by their employers; insecurity about job and income; acute distress that arose from their inability to look after the health issues of children and pregnant women" (Chander et al., 2020, p. 2)
Desire to return to their homeland. Once the lockdown was implemented, the primary concern for most of the migrants was to return safely to their families. Being isolated from the families created more stress and tension among them and caused a lot of growing anxiety about the travel possibilities.

On 19th March 2020, the Indian Railways announced the sudden suspension of passenger trains and, as a consequence, there was a mass exodus of utterly terrified migrant workers. Thousands of migrant workers across Delhi and the National Capital Region (NCR) were seen carrying heavy baggage and wailing children walking on national highways, boarding tractors, and shoving each other around for seats in buses to leave for their homes. The government, upon understanding the problems of jobless migrants to access food and shelter, tried to reassure them by announcing an assistance by an extended scheme under the Prime Minister's Garib Kalyan Yojana (PMGKY). This offered relief packages to the migrants and daily wagers with the aim of blocking any disruptions to their employment besides supporting small establishments. However, this initiative was not satisfactory, because despite these efforts of the government, a huge number of migrants spent restless nights without food, asylum and/or travel facilities (Nanda, 2020). Failure in the implementation of the government's assurance to provide basic necessities such as food and water forced thousands of migrant labourers to flock to the city's bus terminals (Singh, 2020a, 2020b, 2020c). However, not everyone could get on a bus and leave for their homelands (Ram, 2020).

Since most of the public transport was suspended as part of COVID-19 safety precautions, the migrants were stuck at their place of work and felt completely miserable (Chander et al., 2020). Even though they were aware of the risks involved in travelling back to their hometowns, both for them and their families, most of them desperately longed to get back home. They believed that it would be comforting to be with their loved ones during this time of uncertainty of impending death and was increasingly impatient to travel back home. They yearned to go back, so much so that they were even willing to put up with the discomforts of the travel quarantine norms imposed by the government (Chander et al., 2020).

From surveys conducted by NGOs like Stranded Workers Action Network (SWAN), it was found that due to scarcity of money and food, many of the migrants had very little to eat and some were even on the brink of starvation (Staff, 2020; Shahare, 2020). Most of these migrants suffered hunger pangs and police brutality and hundreds of people died tragically enroute to their homelands during the pandemic (Santoshini, 2020).

Fear of losing job. As much intense was the desire of the migrants to go back to their families, so were their worries about losing their jobs. Millions of migrant labourers employed across various sectors like construction, agriculture, manufacturing, transport and other services were stuck in their migrant locations during the lockdown. Even those migrant labourers who did not lose their jobs, as they were employed in essential services, had to suffer from wage-cuts imposed by their employers. They were therefore worried over how they would meet their regular expenses like those on food, clothing, medicines and accommodation. For those who were away from their worksite for several days together, there was absolutely no job security, and this led to a mounting panic in them. On the other hand, those who lost their jobs had the additional worries about whether and how they could return to their hometowns. Owing to the prevailing travel restrictions and the non-availability of transport 
facilities, there was no certainty about whether and when they would be able to travel back. The dread of being forsaken by their employers and the creeping fear of being abandoned with no job, wages or place to stay was indeed a traumatic experience for them (Chander et al., 2020).

Financial distress. As per the certified employment valuation, Indian industries have millions of internal migrant staff who make significant contributions to the economy of India. (Deshingkar and Akter, 2009; Choudhari, 2020). Although India's economic growth is dependent to a great extent on the cheap labour of such migrants who work for even less than the minimum wages, they remained unrewarded and obscure in Delhi and the National Capital Region (NCR), and were excluded from relief funds during the COVID-19 crisis (Shahare, 2020).

The International Labour Organization (2020) has observed that migrant labourers are the worst-hit by the current economic crisis. The costs of basic hygienic products necessary for individual security during the pandemic (such as detergents, soaps, sanitisers) have become prohibitively expensive and unaffordable for the migrants, because they were thrown out of their jobs and had no other sources of income (Srivastava, 2020). Many employers have either fired the migrant workers without any prior notice or have stopped paying them salaries. The financial crisis caused by the COVID-19 pandemic has inflicted severe difficulties for the lower income families in meeting the costs of food, clothing and medicines (Mishra and Sayeed, 2020). Adding to the financial woes of the migrants, the NITI Aayog (a public policy think-tank of the Government of India) reduced food subsidies from 75 to $60 \%$ in rural areas and from 50 to $40 \%$ in urban areas (Gothoskar, 2021). Studies done on earlier recessions (Kumar et al., 2020) have pointed out that the workloss during an economic crisis often leads to "longstanding unemployment and wage impediments, deteriorating or worsening the health of unemployed workers and thereby increasing poverty" (Khanna, 2020, p. 3-4).

Quality of the relief camps. Not all migrants could travel back to their homelands before the lockdown. All those who were left behind were allotted food and accommodation by the government (Singh et al., 2020). Numerous labourers had to remain in extremely tiny and congested rooms with nearly nothing to live on. Seven to eight individuals were confined in a tiny room with practically no ventilation, and no appropriate space to cook food (Shahare, 2020).

In majority of the relief camps there were no essential facilities such as power, light, fan, latrines and water, and most of them were absolutely packed, and the old occupants were not permitting new ones to come in. Consequently, there were a lot of fights, maltreatments and bullying among the migrant groups (Shahare, 2020).

The anxiety of catching the disease, as described in the words of a Dalit migrant as a personal experience account was such, "that we were scared that we might get infected with the virus because there was a COVID-19 positive patient in my neighbouring street ... we did not want to stay anymore in Mumbai because we were anxious of getting the infection through using the public toilet or sharing food because we lived in a slum and we don't have separate toilet and housing; thus we decided that now we shall return to our village" (Pankaj, 2020, p. 5). Although the government had allotted food and shelter for the migrants, it was found that in most of the shelter homes and relief camps people did not receive sufficient quantity and quality food on time. They had to wait for three to four hours in long queues since morning for their meals. Thousands of calls related to scarcity of food were made to the police from these camps on a daily basis (Shahare, 2020).

Shortages in the allotted rations. The report by SWAN that was released on 15th April 2020, stated that, "only 51\%, of who were surveyed, had rations left for less than one day" (Farooqui and Pandey, 2020). It further observed that, "two weeks into the lockdown, only $1 \%$ of the stranded workers had received rations from the government, and three weeks into the lockdown, $96 \%$ of the migrants had not received rations from the government at all, $70 \%$ had not received any cooked food, $78 \%$ had less than Rs.300 left with them and $89 \%$ had not been paid by their employers at all during the lockdown" (Shahare, 2020, p. 6). The distribution of rations was on the basis of the person possessing a ration card, but most of the migrants did not have a permanent residence or necessary legal documents, and therefore were unable to get a ration card.

This distribution system became faulty due to the lack of an inter-state portable ration cards acceptable in all states. The impact of this problem has got aggravated, as a large section of the migrants neither have a valid ID proof nor have been registered under any special schemes set up for them. Although the government has enacted the Inter-State Migrant Workmen Act, 1979 to facilitate the lives and work of migrant labourers, it has remained ineffective due to poor implementation, as per the reports of the Standing Committee on Labour (PRS India, 2020).

An article in The New Indian Express, published on 29 March 2020, reported that about 200 migrant workers belonging to the Soliga tribe were stranded at coffee estates in a village of Kodagu (formerly known as Coorg) district in the Indian state of Karnataka and were running out of food and were living in awful conditions (Chakma, 2020). On the publication of this article, the government of Karnataka reached out to them and distributed rations of rice and pluses and other necessary food products like eggs, ghee and edible oil to the tribal families (Chakma, 2020).

The Delhi Government has developed shelter homes, quarantine homes and relief camps for the migrants and are taking care of about 600,000 individuals, besides providing food to more than 2.2 million migrants under their Free Ration Scheme, facilitated by the One Nation One Ration Card Scheme of the Government of India. Despite this, millions of migrants are still excluded from these schemes and have not received any help from the Government (Mukhra, 2020).

Insufficient health-care facilities. The migrant population including mothers, children, and pregnant women, were deeply apprehensive about their well-being, and had serious concerns about their health inside the shelter homes. This group at large was already predisposed to communicable diseases due to their malnutrition, socio-economic status, occupational hazards, and the poor living conditions (Choudhari, 2020). The deplorable conditions in the relief camps prevented them from following any basic safety precautions like practising social distancing, regular washing of hands, use of sanitiser and masks, that each individual was required to do as part of the standard procedure for fighting COVID-19. Unfortunately, practising these measures was extremely difficult or impossible in their crowded and ill-equipped camp-accommodations, and this has put the group at great risk of contracting the disease (Andrade, 2020; Chander et al., 2020). Even the symptoms of common cold, such as "fever, cough and throat pain" among the people were feared as Covid-infections, which threw everyone into a panic and caused a lot of bitter resentment amongst those living in the community (Chander et al., 2020). 
Hardships of women in the camps. Female migrant workers confronted daunting challenges while living along with unknown men in these shelter homes. One major problem was in using the common toilets with them, which was highly unhygienic and likely to cause infections under the prevailing pandemic conditions. There was no privacy or protection available for the women during day or night. The plight of pregnant women was particularly miserable as they were greatly inconvenienced in these camps and shelter-homes. There were no facilities for regular medical check-up by doctors or for taking scans or conducting the necessary tests.

It was found in one of the surveys that nearly $42 \%$ of the pregnant migrant women did not receive any medical check-ups during the lockdown (Pandit, 2020). All these were highly disconcerting for the women who were forced to live in these camps (Shahare, 2020).

Withdrawal symptoms. Majority of the migrants use one or the other type of substances such as tobacco or alcohol. Therefore, the non-availability of these products during the lockdown has led to severe withdrawal symptoms in many of them. In a study conducted in Bangalore (Chander et al., 2020) a few migrants spoke out that they all have become "sober" due to nonavailability of alcohol and other substances. Some of them even spoke about their withdrawal issues, which caused a lot of frustration in them and resulted in relationship problems, domestic violence, and psychiatric illnesses. Heavier alcohol usage and criminal sexual behaviour have been reported in communities of predominantly single men compared to those living with their families.

Psychological issues. The poor living conditions of the migrants the shortages for the basic necessities have caused severe mental stress to many of them, which got manifested in their lives in the form of relationship problems, substance abuse, alcoholism, sexual exploitation, domestic violence, and psychiatric illnesses (NACP III, 2007; Kumar et al., 2020). Adding further to the burden of the awful shock wave of physical distress caused by the pandemic, there was a gigantic wave of psychological issues among migrant labourers, with deaths due to suicides as its lead sign (Singh, 2020a, 2020b, 2020c). Suicidal tendencies were provoked among the migrants, as they lived constantly under severe financial worries, loneliness, anxiety, fear, and feelings of hopelessness and isolation (Choudhari, 2020). The constant fear of an impending doom of a completely dark future has further intensified their psychological distress and discomfort.

With the imposition of the lockdown, not all were able to go back to their homelands. Instead, they were stranded in the migrant lands with no income but only uncertainty about travelling back home, which made them mentally disturbed and agitated (Singh, 2020a, 2020b, 2020c). As all the workplaces were shut down, there was an increasing panic about whether and when they would be reopened. Even if the workplaces are reopened, there was no guarantee that all the former employees would be hired back. There was a lingering fear in the minds of these displaced workers that the recession in the aftermath of the pandemic would result in large scale firing of employees. This fear and distress accompanied the migrants who travelled to their native lands and at the same time restrained some of them from going back to their native lands (Nanda, 2020).

The living conditions of the migrants also induced distress and concern as they were heavily crammed up and unhygienic, which was the complete opposite of an ideal place to be in during the pandemic. The fear and agony of living in such harsh conditions and the lingering uncertainty about the future gave rise to many psychiatric issues among them, such as anxiety disorders and substance abuse. In a study on migrants, it was found that there is increased risk for the manifestation of schizophrenia and related non affective psychosis among first- and second-generation migrants (Henssler et al., 2019). As most of the migrants belonged to the socio-economically backward classes, they are subjected to much inequity and prejudice from the people in the migrant lands, and were never able to fit in with the new surroundings. Studies from the clinical psychology perspective have found that experiencing discrimination and social exclusion has led to increased rates of psychotic experiences among migrants (Mishra and Sayeed, 2020).

In most of the cases of the migrants, the absence of a caretaker or a family member with them has caused an unceasing feeling of loneliness and frustration (Zhou et al., 2020). There was also a continuous feeling of helplessness caused by their inability to meet the livelihood and health requirements of their families, living away in their homelands. This has greatly deepened their agony of being stuck far away from home (Choudhari, 2020).

Apart from causing harmful effects on the body, the virus has the ability to inflict longstanding psychological disorders such as "depression, anxiety, panic disorder, and psychosomatic manifestations" (Qiu et al., 2020, p. 2). There were several reported attempts of self-harm and suicides by the migrants (Singh, 2020a, 2020b, 2020c). The pathetic situation they are in and the ambiguity about the extent of the crisis created a panic response among the migrants and made them act out frantically. The nagging anxiety levels that were mounting among the masses day by day led them to set out on their travel on foot for several hundred miles in order to reach their destinations, their homelands, with no facility of food or shelter during the journey (Choudhari, 2020).

Although the mental-distress cases were escalating, it was noticed that there was a drastic decline in the number of patients (both new and follow up cases) visiting the psychiatric outpatient services after the lockdown. Apparently, the reluctance to visit the clinics was out of the fear of contracting the virus. However, the danger of ignoring any psychological treatment at a time when they are estimated to be rising holds the possibilities of adverse effects on the efficacy of treatment. In addition, the considerable decline in follow-up visits also paves way to the threat of relapse (Aragona et al., 2020).

Racial discrimination of the North Eastern migrants. It was reported by the Rights and Risks Analysis Group (RRAG) on 26 March 2020, that, during the time-period from 7th February 2020 to $25^{\text {th }}$ March 2020, there were twenty-two incidents (in different parts of the country) of racial discrimination and assaults against individuals from the North East (Chakma, 2020). They were called names such as "Corona", "Chinese", and "Chinki", and were glared at, along with shouting of expletives. India's mongoloid looking citizens were subjected to insults while they were strolling on the roads, doing their shopping or travelling in trains and buses. They were called "Covid", and coercively isolated, even though they had negative COVID-19 certificates. They were denied entry into public places, and were driven out of eateries and shared transports.

Psychosocial issues. The high levels of anxiety and stress induced among the general public by the lockdown during this pandemic was felt more intensely among the migrants, leading to many more psychosocial issues among them. The stress generated in the migrants made them behave in socially unacceptable ways and caused panic attacks on them. Consequently, they started fleeing hastily from the migrant lands. In order to go back to their home 
states at the earliest, they started crowding at the local bus stands and railway stations in desperation, ignoring all lockdown rules. This reckless behaviour of violating the norms of preventive measures resulted in the perpetual vicious cycle of being exposed to infection, quarantine, distress and hostilities (Choudhari, 2020). Although the most pressing need for all migrants at that time was the immediate return to their homelands from the migrant lands, the reverse migration came with a lot of appalling hardships and several other related problems (Tandon, 2020; Wong et al., 2019; Chakma, 2020).

Issues of reverse migration. Owing to circular migration or reverse migration, there was an acute shortage of workers in the urban areas from where the migrant workers had left for their homelands (Srivastava, 2020). This shortage, combined with the new relaxed laws in both occupational and industrial health, compelled the available local workers to work for longer durations than what was actually expected of them, which was in fact against the Factories Act of 1948 (Rivera et al., 2020; Wong et al., 2019). As a result, there was a drastic decline in the resting hours of the workers, which in turn led to the rise in stress and burnout among them and made them more prone to mental health issues (Choudhari, 2020).

The phenomenon of reverse migration has a bigger effect on the indigenous communities in the migrant lands as well. Reverse migration can mop out endangered indigenous Indian communities' inhabitants and eternally ruin the subsistence of several such communities. As there were millions of people belonging to outside communities, such as those from the North East, have migrated to the urban cities in search of work in unorganised sectors, the lockdown induced re-migration would adversely affect the urban economies for want of labourers, as well as lead to the destruction of the economy of the migrants' homelands because of the loss of jobs and income for those families and the resultant food and hunger crisis (Chakma, 2020).

The problems of the migrants did not cease to exist even after their reverse migration to their homelands. On reaching back to their homelands, their problems were mainly about staying in quarantine and the difficulties associated with it (Mishra and Sayeed, 2020).

Issues with quarantine after reverse migration. As part of the travel protocol prescribed for the pandemic-times, all migrants going back to their homelands were expected to be tested for COVID-19 and were expected to stay in self-isolation or quarantine at their homeland-residences for a minimum of fourteen days. Most of the migrants come from poor backgrounds with only a single room in their houses. Under this situation, they had to spend their quarantine period outside their houses. It was reported that in the Purulia district of West Bengal, some migrants spent their quarantine period outside the village limits by sleeping under trees, inside trucks or buses, or in make-shift shelters (Chakma, 2020). Similarly, in the Siwan area of Bihar, the labourers who managed to arrive at their hometowns were placed in extremely small spaces behind an iron gate in an infectious condition. To their good fortune, they were rescued from there on the following day and were transported in trucks to the isolation centres of their respective panchayats (Mishra and Sayeed, 2020).

Since the panchayat-shelters were also makeshift arrangements, there were very few protective measures provided to the residents. As the migrants were crowded in these shelters in high concentration, there was a significant risk of infection. In most places, the migrant labourers were stuck in these makeshift camps for many days, with poor infrastructure and inadequate food supply (Mishra and Sayeed, 2020).
Since the imposition of the lockdown, the media has featured several stories of the pathetic situation of the migrant labourers in various parts of the country. In the Bareli district of Uttar Pradesh, many migrants including women and children were forcefully pushed to clean themselves up in chemical baths as a sanitisation measure (Sammadar, 2020).

In general, the overall condition of the migrants was inexpressibly pathetic. Their worries and adversities did not come to an end. From being stuck in the lockdown in migrant lands to going through the difficulties of reverse migration and the struggles of survival, battling through quarantine and financial crisis during the pandemic-time was a fierce combat they had to wage while trying to stay alive and safe from the risk of starvation and infection.

\section{Conclusion}

This paper is an attempt to assess (based on published research papers) the plight of the migrants during the Covid crisis, in terms of their economic, social and health conditions. It brought into limelight the adversities, vulnerabilities, as well as the physical and psychological distresses and discriminations faced by the migrants under the onslaught of this pandemic in the Indian context, along with the problems of the resultant circular migration. From the survey of the 15 selected studies, it was clear that most of the problems faced by the migrants were due to them having been stranded in the migrated lands due to the lockdown. They were stuck in relief camps that had poor living conditions, with no job or income and, therefore, no means to travel back to their homelands. They became vulnerable to many physical and psychological illnesses, and received hardly any medical care from the government. In addition to suffering from the lack of basic physical facilities and the scarcity in the allocated resources, they also faced social issues such as discrimination and attacks from the local people.

Owing to the unpredictable nature of the pandemic and the uncertain turns it was taking with the passage of time, there was no end in sight for the crisis, and so the migrants couldn't expect any relief from this tragic situation they were locked down in. The government launched several initiatives for the welfare of the migrants. One of them is the "The Aatma Nirbhar Bharat Abhiyaan", through which they distributed free food grains for migrant workers without ration cards for a period of 2 months. Another government program was the "Affordable Rental Housing Complexes for Migrant Workers and Urban Poor", which provided affordable rental housing units under the Pradhan Mantri Awas Yojana (PRSIndia, 2020). Although there were many such initiatives by the government, most of them were poorly implemented, and therefore, they became non-functional and failed to reach the entire migrant population.

Through the present study, the authors conclude that, based on the evaluation of the factors affecting the migrants, it is necessary to adopt immediate interventions for the welfare of the migrants.

Recommendations. One of the most pressing needs of the migrants is to have access to health services, which are equitable, non-discriminatory, and appropriate according to age and gender. In order to ensure maximum effectiveness, these measures must be people-centred and migrant sensitive, so as to deliver services that are culturally and linguistically appropriate because migrants are different from the people in the migrated lands, as they are subjected to different kinds of distress and exploitation.

Additionally, addressing and improving the mental health of the migrants are extremely necessary. Providing regular facilities such as in-person counselling, tele-counselling, therapies and psychosocial services is a necessity. In addition to this, systematic 
assessments must be conducted for early detection of and early interventions for any mental disorders among the migrants. Forming a strong ethical alliance between the local population, health systems, local government, and human rights associations to ensure the welfare of these migrants is also necessary. Furthermore, it is vitally important to prevent the spread of any fake news about the virus and to convey evidence-based accurate information to the public.

A major issue that calls for special attention is the well-being of women and children among the migrants. Women should be provided adequate services for maintaining reproductive health, maternal health, postnatal care, paediatric care and preventive/ remedial measures for dealing with domestic or sexual abuse. These services must be focused on risk assessment and treatment for improving their health conditions and must not be used to screen out their health issues; nor should they be used as a tool for discrimination or for enforcing any restrictions. The migrant community must also be given priority for vaccination by the local administrations because of their particular vulnerability to the virus-infection. Furthermore, since the major cause for their health issues is the deplorable living conditions of the relief camps, the respective state governments should take the necessary steps to improve the living conditions in all relief camps.

It is essential to monitor health-care practices of the migrants and generate a repository of relevant health-care information during the pandemic period, which can be used to support future studies on the health issues of migrants during any Covid-like pandemics. Moreover, this will also facilitate sharing of healthrelated information between states, so as to facilitate the implementation of effective treatment strategies for migrants from various places.

A major social issue among the migrants is their fear of losing their jobs, income and housing. On these matters also it is the governments that can help, as they can take unbiased actions in case of any exploitation or labour complaints regarding their right to stay and work. It will also be of help if assistance is provided to the migrants to form associations and cooperative societies to support the livelihood of those who have returned to their native lands.

In view of the need to effectively manage the health issues of the migrants, it is necessary to give special attention to the migrants' housing facilities, as their present unhygienic living conditions are a breeding ground for innumerable diseases. Government initiatives like The Aatma Nirbhar Bharat Abhiyaan, must be properly implemented. Similarly, NGOs and aid agencies should be persuaded to raise funds to construct affordable housing units, which should be made available to migrants for minimal rents (PRSIndia, 2020). For migrants who are not able to afford even these minimum-rental houses, the relief camps must be kept open with better facilities for a longer period.

Another social issue as explained in the SWAN report is the irregular and uneven distribution of basic necessities among the migrants (Shahare, 2020). Hence, there is a need for a universal and uniform mechanism for the distribution of both financial aid and essential items such as grains, medicines, and water to the migrant families. In order to ensure efficient distribution of financial aid and basic necessities among the migrants, it will be a good idea to entrust this work to the respective "panchayats" (the Indian local administrative councils operating at the village, block and district levels) to register and enrol these migrants and distribute these resources to them as per their eligibilities. Since they are already facing severe financial difficulties, subsidies must be increased as opposed to initiatives like NITI Aayog (Gothoskar, 2021).

A major political issue faced by the migrants is the absence of a body or agency to represent them in the respective state governments of the migrated lands. Since the migrants are only entitled to vote in their home constituency, and not in their migrated states, their political clout is limited and therefore their voices are rarely heard (Deshingkar and Akter, 2009). In order to present their demands and concerns to the governmental agencies, they have to be a part of a legitimate political system, which is authorised to represent them in these migrated lands.

There is an immediate need to push for a pro-migrant attitude in the general society, a better acknowledgement of the contribution of the migrants to the society, and the adoption of a proactive role in educating them and safeguarding their labour rights. This study further emphasises the urgent need to revise the national migration policies, which should help assist and protect the migrants and the returnee migrants who are either travelling from or to the areas affected by the pandemic.

Limitations. One of the main limitations of the reviewed studies was the inability to make any alterations with the brief interactive interventions with the migrants as their distress levels were much higher. These studies were restricted due to being retrospective single-centre studies and so generalising these findings across all services are difficult.

This review limited its focus to migrant workers alone and passed over the similar issues faced by the emigrants who have returned to the country post lockdown and also on the immigrants who were stuck in the country due to the lockdown rules and regulations. These two groups also have undergone trauma along the same lines as the migrant workers group and, therefore, future studies focusing on these are highly relevant and in need.

\section{Data availability}

The data that support the findings of this study were derived from the databases (PubMed, Scopus, PsychNet, and Google Scholar) available in the public domain.

Received: 30 January 2021; Accepted: 20 September 2021; Published online: 14 October 2021

\section{References}

Aragona M, Barbato A, Cavani A et al. (2020) Negative impacts of COVID-19 lockdown on mental health service access and follow-up adherence for immigrants and individuals in socio-economic difficulties. Public Health $186: 52-56$

Amin S (eds) (2018) Modern migrations in western Africa. Routledge

Andrade C (2020) COVID-19: humanitarian and health care crisis in a third world country. The J Clin Psychiatry 81(3):1-1

Babu B, Kusuma Y, Sivakami M et al. (2017) Living conditions of internal labour migrants: a nationwide study in 13 Indian cities. IJMBS 3(4):328-351

Bhagat B, Keshri K (2020a) Internal migration in India in internal migration in the countries of Asia. Springer, Cham, https://doi.org/10.1007/978-3-030-44010 7_11

Bhagat B, Reshmi S, Sahoo H et al. (2020) The COVID-19, migration and livelihood in India: challenges and policy issues. Migr Lett 17(5):705-18

Census of India (2011) Census schedule: household. Office of the Registrar General and Census Commissioner, New Delhi

Chakma D (2020) COVID-19 in India: reverse migration could destroy indigenous communities. International Work Group for Indigenous Affairs, Copenhagen, http://www.indigenouslawyers.org/resources/covid-19-in-india-reversemigration-could-destroy-indigenous-communities/

Chander R, Murugesan M, Ritish D et al. (2020). Addressing the mental health concerns of migrant workers during the COVID-19 pandemic: An experiential account. Int J Soc Psychiatry, 1-4. https://doi.org/10.1177/ 0020764020937736

Choudhari R (2020) COVID 19 pandemic: mental health challenges of internal migrant workers of India. Asian J Psychiatr 54:102254 
Colla C, Barbieri A, Ferreira C (2017) The relationship between migration and commuting at curitiba metropolitan region (CMR) and its interaction with the labour market. In 2017 International Population Conference. IUSSP, Cape Town, South Africa

Dandekar A, Ghai R (2020) Migration and reverse migration in the age of COVID19. Econ Polit Wkly 55(19):28-31

Deshingkar P, Akter S (2009) Migration and human development in India: Human Development Research Paper (HDRP). UNDF Series. 13

Farooqui H, Pandey, S (2020) Social security for informal workers in India. CPR

Ghosh N (1985) Fundamentals of Population Geography. Sterling Publishers

Gomathi R (2014) Quality of life of migrant construction workers in Coimbatore city. Doctoral dissertation, Avinashilingam Deemed University For Women

Gothoskar S (2021) NITI Aayog's proposal to cut food subsidies will worsen India's rising hunger problem. The Wire. https://thewire.in/government/niti-aayogsproposal-to-cut-food-subsidies-will-worsen-indias-rising-hunger-problem. Accessed Mar 12

Haas A, Osland L (2014) Commuting, migration, housing and labour markets: complex interactions. Urban Stud 51(3):463-476. https://doi.org/10.1177/ 0042098013498285

Henssler J, Brandt L, Müller M (2019) Migration and schizophrenia: meta-analysis and explanatory framework. Eur Arch Psychiatry Clin Neurosci. 1-11

Khanna A (2020) Impact of migration of labour force due to global COVID-19 pandemic with reference to India. J Health Manag 181-191

Kishore K, Kiran V (2013) Labor migration-a journey from rural to urban. JBM\&SSR 2(5):61-66

Kumar K, Mehra A, Sahoo S et al. (2020) The psychological impact of COVID-19 pandemic and lockdown on the migrant workers: a cross-sectional survey. Asian J Psychiatry 53:102252

Kumar R, Vashisht P (2009) The global economic crisis: impact on india and policy responses. SSRN e Journal. https://doi.org/10.2139/ssrn.1606482

Kusuma S, Pandav S, Babu V (2014) Socio-demographic profile of socioeconomically disadvantaged internal migrants in Delhi. J Identity Migr Stud $8: 2$

Londhe V (2020) The impact of COVID-19 on India's migrant workers. Sedex. https://www.sedex.com/the-impact-of-covid-19-on-indias-migrant-workers/. Accessed May 62020

Mishra A, Sayeed N (2020) Covid-19 and migrant workers: clinical psychologists' viewpoints. L. S. S. Manickam (Ed.), COVID-19 pandemic: Challenges and responses of psychologists from India. The Editor, Thiruvananthapuram, p. $43-56$

Mukhra R (2020) COVID-19 sets off mass migration in India. Arch Med Res $736-738$

NACP III (2007) National AIDS Control Organization, Ministry of Health and Family Welfare: GOI Targeted intervention for migrants, operational guidelines. Ministry of Health and Family Welfare. Government of India

Nanda J (2020) Circular migration and COVID-19. SSRN e Journal https://doi.org/ $10.2139 /$ ssrn. 3683410

Nelson V (2020) Suicide prevention india foundation. Retrieved from The Wire: http://www.rfi.fr/en/international/20200514-mental-illness-suicides-on-therise-in-india-during-covid-19-lockdown. Accessed Jul 242020

Nirmala (2020) Decent work for migrant workers in india. Retrieved from UN india covid response. https://in.one.un.org/page/decent-work-for-migrantworkers-in-india/

Pandit A (2020) 1 in 4 migrants went home on foot during lockdown: Survey. The Times of India. https://timesofindia.indiatimes.com/india/1-in-4-migrantswent-home-on-foot-during-lockdown-survey/articleshow/ 77474165.cmsAccessed Aug 112020

Pankaj (2020) The Panchshil Buddha Vihar Group: Dalit migrant life and group solidarity during the pandemic. Soc Work Groups. 312- 317

PRSIndia (2020) Summary of announcements: Aatma Nirbhar Bharat Abhiyaan. https://www.prsindia.org/report-summaries/summary-announcementsaatma-nirbhar-bharat-abhiyaan Accessed May 202020

Qiu J, Shen B, Zhao M (2020) A nationwide survey of psychological distress among Chinese people in the COVID-19 epidemic: implications and policy recommendations. GPSYCH 33:2

Ram R (2020) The COVID-19, migration and livelihood in india: challenges and policy issues: challenges and policy issues Migrat Lett 17(5):705-718

Raj H (1981) Fundamentals of demography. Surjeet Publications, Delhi

Rivera S, Akanbi M, O'Dwyer C et al. (2020) Shift work and long work hours and their association with chronic health conditions: a systematic review of systematic reviews with meta-analyses. PLoS ONE 15(4):e0231037

Rolland S (2020) COVID-19 pandemic: applying a multisystemic lens. Fam. Process 59(3):922-936

Sammadar R (2020) Borders of an epidemic: COVID-19 and migrant workers. Int J Commun Soc Dev 2(2):286-287. https://doi.org/10.1177/ 2516602620935679
Santoshini S (2020) What a lockdown means when home is hundreds of miles away. Christian Science Monitor 13. Retrieved from The Christian Science Monitor. https://www.csmonitor.com/World/Asia-South-Central/2020/0413/ What-a-lockdown-means-when-home-is-hundreds-of-miles-away

Shahare B (2020) Covid-19 lockdown and fate of migrant labours in Delhi. J Ady Res Humanit Soc Sci. 7(1):9-13

Singh P (2020a) Migrant crisis after lockdown in India during the COVID-19 pandemic: an invisible mental health Tsunami. Prim. Care Companion CNS Disord 22(4):0-0

Singh P (2020b) Migrant crisis after lockdown in India during the COVID-19 pandemic. Prim Care Companion CNS Disord 22(4). https://doi.org/10.4088/ pcc.20com02710

Singh P, Arun P, Chavan S (2020) Efforts to minimize the impact of lockdown on migrant workers in India during the COVID-19 pandemic. Prim. Care Companion CNS Disord 22(3):0-0

Singh P (2020c) Mental health of migrant laborers in COVID-19 pandemic and lockdown: challenges ahead. Indian J Psychiatry 233-234

Singh S (2021) Explained: Indian migrants, across India. The Indian Express. https://indianexpress.com/article/explained/coronavirus-india-lockdownmigran-workers-mass-exodus Accessed Mar 42021

Sinha K (2005) Human migration: concepts and approaches. Foldr Ert $3(4): 403-414$

Srivastava R (2020) Understanding circular migration in its nature and dimensions, the crisis under lockdown and the response of the state. IHDI WP IHDI WP $4: 1-30$

Staff W (2020) Government has created an archive of distress, a museum of misery for migrant workers. Retrieved from The Wire: https://thewire.in/rights/ migrant-workers-covid-19-lockdown-crisis-swan-report. Accessed Jun 14 2020

Tandon R (2020) COVID-19 and mental health: preserving humanity, maintaining sanity, and promoting health. Asian J Psychiatr 51:102256. https://doi.org/ 10.1016/j.ajp.2020.102256

Virupaksha G (2014) Migration and mental health: an interface J Nat Sci Biol Med 5:233-239

WHO Coronavirus (COVID: 19) (2020) World Health Organisation. https:// www.who.int/health-topics/coronavirus\#tab=tab_1. Accessed Jan 102020

Wong K, Chan H, Ngan C (2019) The effect of long working hours and overtime on occupational health: a meta-analysis of evidence from 1998 to 2018. Int J Environ Res Public Health 16(12):2102

Zhou X, Snoswell L, Harding E et al. (2020) The role of telehealth in reducing the mental health burden from COVID-19. Telemed e-Health 26(4):377-379

\section{Acknowledgements}

The author(s) received no financial funding for the research, authorship and/or publication of this article.

\section{Competing interests}

The authors declare no competing interests.

\section{Additional information}

Correspondence and requests for materials should be addressed to Eslavath Rajkumar.

Reprints and permission information is available at http://www.nature.com/reprints

Publisher's note Springer Nature remains neutral with regard to jurisdictional claims in published maps and institutional affiliations.

Open Access This article is licensed under a Creative Commons Attribution 4.0 International License, which permits use, sharing, adaptation, distribution and reproduction in any medium or format, as long as you give appropriate credit to the original author(s) and the source, provide a link to the Creative Commons license, and indicate if changes were made. The images or other third party material in this article are included in the article's Creative Commons license, unless indicated otherwise in a credit line to the material. If material is not included in the article's Creative Commons license and your intended use is not permitted by statutory regulation or exceeds the permitted use, you will need to obtain permission directly from the copyright holder. To view a copy of this license, visit http://creativecommons.org/ licenses/by/4.0/

(c) The Author(s) 202 